\title{
Spatial Distribution of Cloud Physical Parameters and Cloud Radiative Forcing over the Indian Summer Monsoon Region
}

\author{
Pooja Rana \\ ${ }^{1}$ MOSDAC Research and Training Division, Space Applications Centre, Ahmedabad, India \\ ${ }^{2}$ Physics Department, Gujarat University, Ahmedabad, India \\ *Corresponding Author: puji1888@gmail.com, Tel.: +91-7600673987
}

Available online at: www.isroset.org

Received: 04/Jun/2018, Revised: 12/Jun/2018, Accepted: 22/Jun/2018, Online: 30/Jun/2018

\begin{abstract}
Twenty seven years (1983-2009) of International Satellite Cloud Climatology Project (ISCCP) cloud data and nine years (2001-2009) of Clouds and the Earth's Radiant Energy System (CERES) top of atmosphere cloud radiative forcing data have been used to study the spatial distribution of clouds and the radiative forcing exerted by them over the Indian summer monsoon region. During the Indian summer monsoon season of June - September, cloud cover amount and cloud optical depth are more over the India and the adjoining Bay of Bengal region when compared to other seasons. Cloud top temperature of these monsoon clouds are lower (i.e., taller) in summer season when compared to other seasons. CERES data suggest that monsoon clouds exert a net cooling effect (net cloud radiative forcing is negative) which is uncommon over the tropical deep convective regions.
\end{abstract}

Keywords - Cloud cover amount, Cloud optical depth, Cloud top temperature, Cloud radiative forcing, Indian monsoon

\section{INTRODUCTION}

Cloud macro-physical properties such as cloud cover amount, cloud top height, etc., and cloud micro-physical properties such as cloud droplet size, liquid-ice phase, etc., play a key role in cloud-radiation interaction [1] [2] [3]. For example, shallow stratus clouds have a tendency to cool, whereas thin cirrus clouds have a tendency to warm the earth-atmosphere system [4] [5]. Cloud climatology study is necessary to determine the extent to which seasonal changes of clouds affect the Earth's radiation budget. The climatological distribution of clouds is strongly coupled to large-scale circulation [6].

An understanding of the mean features of the monsoon is necessary before discussing how monsoon varies. The climatological distribution of cloud cover amount, cloud optical thickness and cloud top temperature over India during the summer monsoon season are very much important to understand the Indian summer monsoon.

During the Indian summer monsoon season of June to September, clouds appear to have spatially inhomogeneous physical properties over the Indian summer monsoon region. Windward and leeward sides of the Western Ghat mountain, semi-arid regions of West India, and the monsoon trough region are expected to have different cloud physical properties and cloud radiative forcing because of the large differences in spatial distribution of water vapor availability and other meteorological parameters. Hence, clouds with different cloud physical properties are expected to interact differently with incoming solar and outgoing terrestrial radiations during different seasons [7]. Section I contains introduction of the cloud physical properties and cloud radiative forcing and section II defines objectives of the study. Description of cloud and cloud radiative forcing data and methodology are described in section III. The spatial distribution of cloud cover amount, cloud optical depth, cloud top temperature and cloud radiative forcing during different seasons are discussed in section IV. Association between longwave and shortwave radiative forcing is also discussed in section IV. Conclusion of the work is provided in section $\mathrm{V}$.

\section{OBJECTIVE}

Objectives of the present study are: -

(1) Understand the climatological distribution of important cloud physical parameters such as cloud cover amount, cloud optical depth and cloud top temperature over the Indian summer monsoon region during different seasons.

(2) Radiative forcing of the clouds over the Indian summer monsoon region.

\section{DATA AND METHODOLOGY}

The cloud cover amount, cloud top temperature, and cloud optical depth data of the International Satellite Cloud 
Climatology Project (ISCCP) have been used to study the cloud physical properties over the Indian summer monsoon region [6] [4]. The monthly ISCCP cloud data available during 1983-2009 at $2.5^{\circ}$ latitude $\times 2.5^{\circ}$ longitude grid is used for the study. The Clouds and the Earth's Radiant Energy System (CERES) data set available at a spatial resolution of $1^{\circ}$ latitude $\times 1^{\circ}$ longitude have been used to study the cloud radiative forcing [1]. This data available during 2001-2009, is considered. The cloud and cloud radiative forcing data were download from http://isccp.giss.nasa.gov and http://ceres.larc.nasa.gov respectively. The study area is confined between $0^{\circ} \mathrm{N}$ to $40^{\circ}$ $\mathrm{N}$ latitudes and $60^{\circ} \mathrm{E}$ to $100^{\circ} \mathrm{E}$ longitudes during different seasons [December to February (DJF), March to May (MAM), June to August (JJA) and September to November $(\mathrm{SON})]$.

\section{RESUlts AND DiscusSiON}

\section{Cloud Physical Properties}

The 27-year (1983-2009) average total cloud cover amount (CCA), cloud top temperature (CTT), and cloud optical depth (COD) computed from monthly ISCCP cloud data during the different seasons are shown in Fig. 1- 3. Cloud cover amount is the fractional area (pixel) covered by clouds as seen from satellites. The cloud cover amount is more than $90 \%$ over the Indian summer monsoon region during June to August (JJA), while cloud cover amount is less than $30 \%$ over the Arabian Sea in DJF and MAM seasons. It is clear that the shifting of CCA is regulated by two different monsoon systems over the Indian sub-continent, one is summer monsoon (figure $-\mathrm{c}$ ) and second is winter monsoon (figure $-\mathrm{d}$ ). During SON, maximum percentage of CCA is found over the eastern parts of the equatorial Indian Ocean and Peninsular India associated with winter monsoon. The CCA is low over the Indian landmass during DJF ( about $20 \%$ ) and MAM (less than $50 \%$ ).

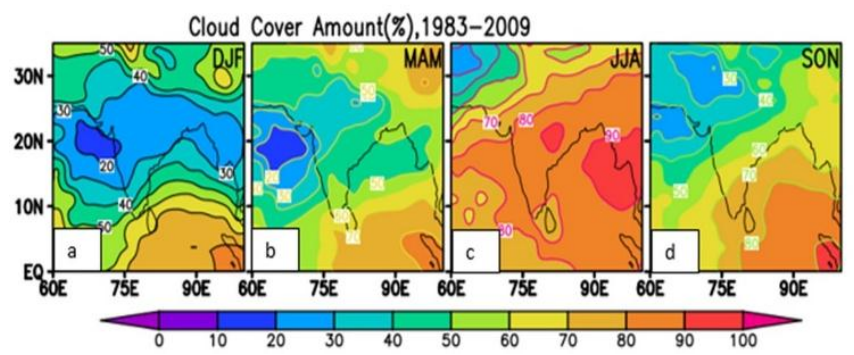

Figure 1 Twenty seven years (1983-20009) average seasonal distribution of cloud cover amount (\%) during (a) DJF, (b) MAM, (c) JJA, and (d) SON over the Indian summer monsoon region using ISCCP data.

COD represents the optical thickness of the clouds at visible wavelengths. Figures 2 (a-d) show the COD over the Indian sub-continent during different seasons. The COD is more than 6 over the west coast of India, central India and Bay of
Bengal during Indian summer monsoon season (JJA) whereas it is less than 2 in DJF and MAM.

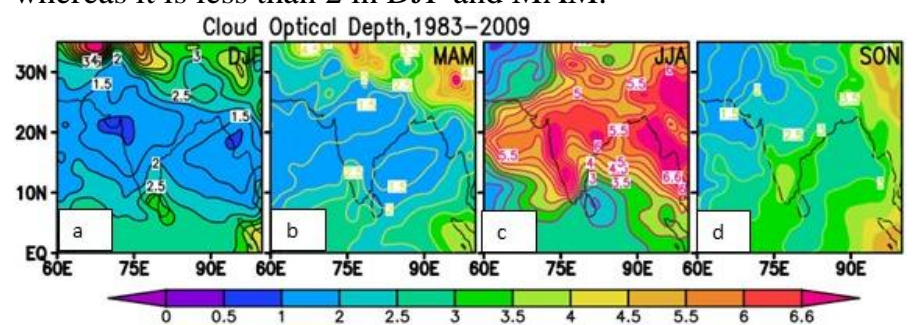

Figure 2 Twenty seven years (1983-20009) average seasonal distribution of cloud optical depth (unit less) during (a) DJF, (b) MAM, (c) JJA, and (d) SON over the Indian summer monsoon region using ISCCP data.

Figures 3(a-d) represents the CTT for different seasons averaged during 27 years (1983-2009). CTT represents the physical temperature of clouds and it is measured in Kelvin. The CTT is more over the Arabian sea and the Bay of Bengal during DJF (more than $290 \mathrm{~K}$ ) and MAM (approximately $280 \mathrm{~K}$ ), whereas it is lower over the Bay of Bengal during JJA (about $250 \mathrm{~K}$ ). The reason behind higher cloud top temperature (lower height) over the Arabian sea is the presence of low level clouds during JJA and other seasons. The maximum value of CTT goes up over the Bay of Bengal during DJF and MAM because of the presence of shallow clouds.

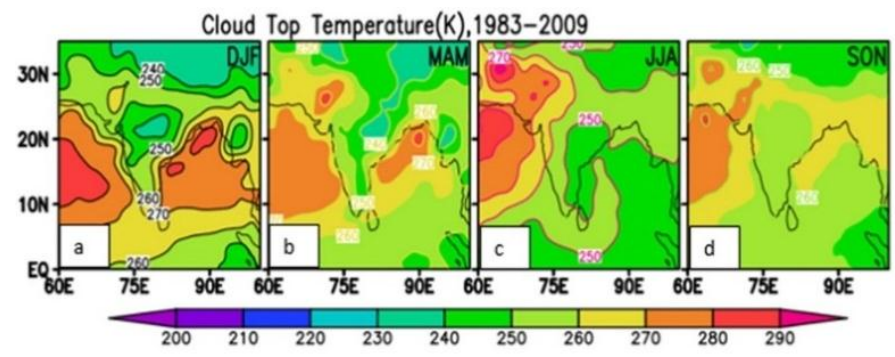

Figure 3 Twenty seven years (1983-20009) average seasonal distribution of cloud top temperature(K) during (a) DJF, (b) MAM, (c) JJA, and (d) SON over the Indian summer monsoon region using ISCCP data

\section{Cloud Radiative Forcing}

Clouds play an important role which influence the radiation balance of the Earth-atmosphere system either positively or negatively [8] [3]. To study the role of clouds on Earth radiation budget, cloud radiative forcing is the important parameter. In this section, cloud radiative forcing is studied using the CERES data over the Indian summer monsoon region. In figure 4(a-d), nine years average (2001-2009) net cloud radiative forcing (NCRF) during different seasons (DJF, MAM, JJA, and SON) are shown.

Over the Arabian Sea during June to August (JJA) cooling is observed. 


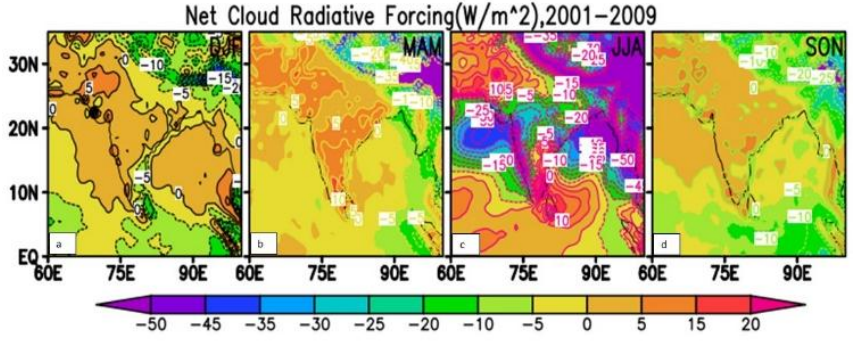

Figure 4 Nine years (2001-20009) average seasonal distribution of net cloud radiative forcing $\left(\mathrm{Wm}^{-2}\right)$ during (a) DJF, (b) MAM, (c) JJA, and (d) SON over the Indian summer monsoon region using CERES data.

From the below figure 4(a-d) it is found that the cooling is more over the Arabian Sea (negative NCRF). Though the Indian monsoon region is within the tropical region, monsoon clouds are exerting a cooling effect.

The scatter plots between shortwave cloud radiative forcing (SWCRF) and longwave cloud radiative forcing (LWCRF) for four different regions viz., (1) Arabian Sea during JJA (NCRF is negative but CTT is more compared to Bay of Bengal), (2) East Indian Ocean during MAM (NCRF is negative but the clouds are colder) (3) Bay of Bengal during JJAS and (4) Srilanka during JJAS (NCRF is marginally negative) from $2001-2009$ ffigures 5 (a-d) \}. The ratio between SWCRF and LWCRF (N) is also calculated for theses area.

The scatter plots suggest that (a) SWCRF and LWCRF are is near balance over the East Indian Ocean, (b) magnitude of SWCRF is more than LWCRF over the Arabian Sea [net cooling], (c) magnitude of LWCRF more than SWCRF at Srilanka (net warming).

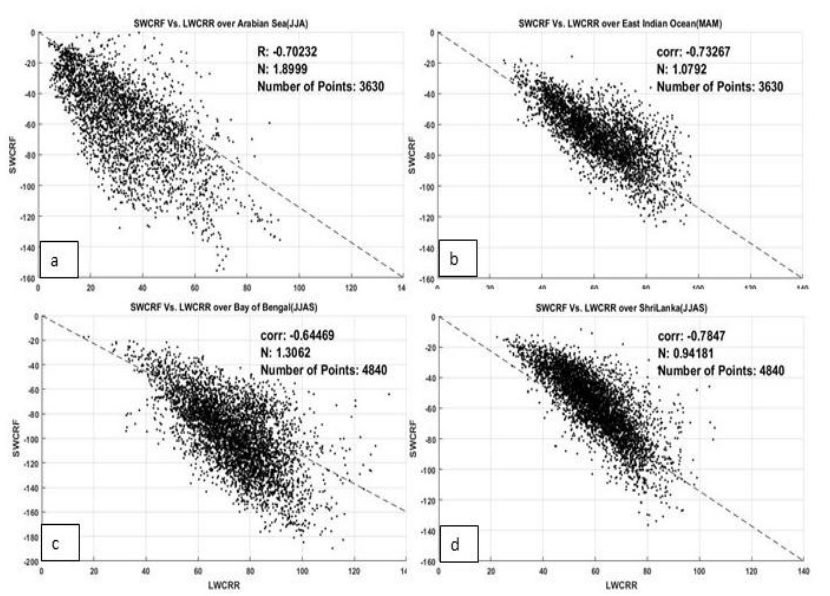

Figure 5 scatter plots between SWCRF and LWCRF over different regions (a) Arabian Sea during JJA, (b) East Indian Ocean during MAM, (c) Bay of Bengal during JJAS, (d) Srilanka during JJAS using CERES data.

\section{CONClusion AND Future SCOPE}

The spatial distribution of cloud physical properties, and cloud radiative forcing over the Indian summer monsoon region during pre-monsoon, monsoon, post-monsoon and winter seasons were investigated using satellite data. Cloud cover amount is higher over the Indian monsoon region during peak monsoon season. Cloud optical depth is also higher during this season. The cloud top temperature is comparatively less (taller clouds) in the monsoon season than other seasons. Net cloud radiative forcing is negative (cooling) over the Indian monsoon region in peak monsoon months.

\section{ACKNOWLEDGMENT}

Author is extremely grateful to the Director, Space Applications Centre, Ahmedabad for providing necessary facilities for the research and providing research fellowship. Author is thankful to the Deputy Director, Earth, Ocean, Atmosphere, Planetary Sciences and Applications Area, Group Head, MOSDAC Research Group, and Head, MOSDAC Research and Training Division, SAC for their encouragement and support throughout the study. The cloud data were obtained from http://isccp.giss.nasa.gov and cloud radiative forcing data http://ceres.larc.nasa.gov.

\section{REFERENCES}

[1] V. Sathiyamoorthy, B. P. Shukla and P. K. Pal, "A study on radiative properties of Indian summer monsoon clouds," Meteorol Atmos Phys, 2011.

[2] J. T. Kiehl, "On the observed near cancellation between longwave and shortwave cloud radiative forcing in tropical regions," J Clim, 559-565, 1994.

[3] B. C. Weare, "Climatic variability of cloud radiative forcing," Quart J Roy Meteor Soc, 1055-1073, 1997.

[4] V. Sathiyamoorthy, P. K. Pal and P. C. Joshi, "Intraseasonal variability of the tropical easterly jet," Meteorol Atmos Phy, 2007.

[5] V. Sathiyamoorthy, P. K. Pal and P. C. Joshi, "Influence of the upper- tropospheric wind shear upon cloud radiative forcing in the Asian monsoon region," J Clim., 17, 2725-2735, 2004.

[6] W. B. Rossow , "International Satellite Cloud Climatology Project (ISCCP) - Documentation of new cloud data sets WMO/ TD-737, World," 1996.

[7] M. Rajeevan and J. Srinivasan, "Net cloud radiative forcing at the top of the atmosphere in the Asian monsoon region," J Clim, 650 657,2000 .

[8] E. F. Harrison, B. R. Barkstrom, V. Ramanathan, R. D. Cess and G. G. Gibson, "Seasonal variation of cloud radiative forcing derived 
from the Earth Radiation Budget Experiment," J. Geo- phys. Res., p. 18687-18703, 1990.

[9] D. Sikka and S. Gadgil, "On the maximum cloud zone and the ITCZ over Indian longitudes during the southwest monsoon," Mon. Wea. Rev., p. 1840-1853, 1980.

\section{AUTHOR PROFILE}

Miss Pooja Rana completed M.Sc (Physics) from Ram Chandra Uniyal Govt. P.G. College, HNBGU,Srinagar Garhwal in 2011 and M.Tech (Remote Sensing) from Banasthali University, Newai, in 2013. She is currently pursuing $\mathrm{Ph}$. D. in Gujarat University and currently working as a

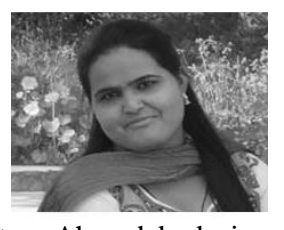
research scholar at Space Applications Centre, Ahmedabad since 2014. Her area of intrests are Atmoshperic Physics, Meteorology, Remote Sensing, GIS. She has 4 years of research experience. 